\title{
STUDY ON DEGRADATION OF FERTILIZER AND PESTICIDES USING LYSIMETER
}

\author{
Vedaprada $\mathbf{R}^{1}$, Sadashiva Murthy B. $\mathbf{M}^{\mathbf{2}}$, Mahadevaswamy $\mathbf{M}^{\mathbf{3}}$, Madhukar $\mathbf{M}^{\mathbf{4}}$ \\ ${ }^{1}$ Assistant Professor, Department of Civil Engineering, NIE, Mysore, Karnataka, India \\ ${ }^{2}$ Professor, Department of Environmental Engineering, SJCE, Mysore, Karnataka, India \\ ${ }^{3}$ Professor, Department of Environmental Engineering, SJCE, Mysore, Karnataka, India \\ ${ }^{4}$ Research Scholar, Department of Environmental Engineering, SJCE, Mysore, Karnataka, India
}

\begin{abstract}
Agriculture is the main occupation in India. Growing demand for food or a result of increasing population has led to a substantial increase in the production of agrochemicals like pesticides and fertilizers resulting in a continued contamination of environment including water bodies. The Lysimeter will allow us to better monitor below ground processes and measurements of nutrients, pesticides, and moisture content with minimal disturbance, both of which are extremely difficult to perform in the field. The Lysimeter were made up of cast iron, $1.2 \mathrm{~m}$ diameter, and $1.5 \mathrm{~m}$ length. Ports were provided at each depth of $0.5 \mathrm{~m}$ to collect samples up to $1.5 \mathrm{~m}$. Lysimeter is installed in field in undisturbed condition. The experiment was initiated in June 2009 at the krishi vigyan Kendra farm (kupparvalli, suttur, Nanjangud). Lysimeter were used to study the leaching of fertilizers and pesticides in paddy field. The leachate samples collected from the field (Lysimeter) were analyzed for nitrate, phosphate, pH, conductivity, and Chlorpyriphos. Chlorpyriphos concentration showed a decreasing trend with depth this is may be due to reason as the pesticide moves through the soil it gets absorbed by organic carbon and degraded by the microorganism.
\end{abstract}

Keywords: Pesticides, Lysimeter, Chlorpyriphos, Groundwater

\section{INTRODUCTION}

Excess use of fertilizers and pesticides has caused soil and groundwater pollution. Non-point sources are often responsible for nitrates and pesticides in groundwater. Increasing concerns about environmental contamination have emphasized the need for information about the fate and transport of agricultural chemicals in soil. The transport process involves the distribution of the chemical between the aqueous phase and the soil phase, and is dominated by solute solvent and solute soil interactions [1]. Nitrate is very soluble and unless intercepted and taken up by plant roots leach down in the soil along with irrigation or rain water or it is carried away by runoff. Phosphorus is rapidly retained as insoluble inorganic compounds and sorbed to soil surfaces. Therefore, the losses of soluble phosphate in surface flow and run off tend to be quite low [2].

New Lysimeter test systems take this into account and enable the measurement of pesticide volatilization and mineralization from Lysimeter surfaces. Lysimeter experiments can be repeated for a range of soil conditions, subjected to range of plausible boundary conditions. Further, it is generally accepted that the leaching observed in Lysimeter may give a good indication on the vulnerability of a specific soil towards leaching. Finally, Lysimeter data can be explored to evaluate the performance of point scale models predicting pesticide leaching [3]. Keeping this in view, Lysimeter were used to study the environmental fate of fertilizer and pesticides. Lysimeter studies offer a good way of conducting controlled experiment under field conditions. Park et al. (2005) [4] studied on the environmental fate of the herbicide molinate in a ricepaddy-soil Lysimeter. The ${ }^{14} \mathrm{C}$ radioactivity in the Lysimeter soil decreased with increased soil depth and decreased organic matter content.

Lysimeter design is typically thought of as being conceptually simple, when in reality the design, installation, and operation of Lysimeter is often counterintuitive, due to the complexities of flow through unsaturated soil systems. The main differences between Lysimeter and the field are that the Lysimeter have (i) a limited root zone volume and (ii) side and bottom boundary conditions determined by the container. While both problems can be resolved by assuring sufficient Lysimeter size, much deeper and thus more expensive and bulky Lysimeter are needed to solve the problem of undesirable saturation conditions at the lower boundary. Lateral diversion can be one of the primary sources of error with Lysimeter if the areal extent of the Lysimeter is insufficient and the Lysimeter does not have vertical sidewalls. Lysimeter that are too small and collect too little water underestimate the percolation rate. In general, the relative importance of sidewall flow can be minimized by increasing the surface area of the Lysimeter. Cylindrical Lysimeter are provided to avoid preferential flow which may occur in rectangular Lysimeter. A Lysimeter study must not suffer from inaccuracy due to the design of the Lysimeter [5]. 


\section{EXPERIMENTAL METHODOLOGY}

The site identified for Lysimeter study is a ten acre land cultivated by krishi vigyan Kendra situated in kupparvalli Village, Nanjangud Taluk of Karnataka, Mysore district which is $31.3 \mathrm{~km}$ away from Mysore situated in the southern dry zone and located at $12^{\circ} 07^{\prime} 20^{\prime \prime} \mathrm{N}, 76^{\circ} 41^{\prime} \mathrm{E}$ and $660 \mathrm{~m}$ in the Deccan Plateau Region of the South Indian Peninsular. The region has bimodal distribution of rainfall benefited by both south west (May to Sept) and north east (Oct-Nov) monsoon with an annual rainfall of $697.0 \mathrm{~mm}$. Generally, the soils where Lysimeter were installed have high water holding capacity and low organic matter \& phosphorus and medium total nitrogen \& potash. The assortment of crops harvested includes paddy. The satellite view of krishi vigyan Kendra farm and Lysimeter installed in krishi vigyan Kendra farm is located at $12^{\circ} 08^{\prime} 39^{\prime \prime} 53^{\prime} \mathrm{N}$, $76^{\circ} 47^{\prime} 12^{\prime} \mathrm{E}$ is shown in Fig 1. The nutrient nourishment to the crops is through NPK, Urea, zinc sulphate green manure and micronutrients Lysimeter was installed in the field in an undisturbed condition with the help of JCB as shown on Fig 2. The Lysimeter was installed in such a place, so that all the drainage water from the other plots will pass through this plot before draining away from the paddy field.

\subsection{Lysimeter Design}

Based on previous studies and considering the limitations of Lysimeter, an appropriate diameter of $1.2 \mathrm{~m}$ and $1.5 \mathrm{~m}$ depth, Lysimeter was fabricated using cast iron material.
Provision was also made for collecting samples from sample ports each at $0.5 \mathrm{~m}$ depth up to $1.5 \mathrm{~m}$ depth. A pit was also dug adjacent to Lysimeter in the field up to a depth of $1.5 \mathrm{~m}$ to collect sample from Lysimeter.

\subsection{Field Observations}

Before planting of paddy crop soil samples were taken from Lysimeter plot to analyze the physico-chemical properties of soil. The plot was monitored from July to December 2009. Before $\mathrm{N}\left(\mathrm{NO}_{3}\right) \mathrm{P}\left(\mathrm{HPO}_{3}\right) \mathrm{K}\left(\mathrm{K}^{++}\right)$fertilizers were applied as basal fertilizers the experimental paddy field was ploughed on September 5th 2009. Cultural operations (Fertilizing, Tilling, Planting, Harvesting, etc.) are normally performed on the Lysimeter to simulate field practices and to assure that crop development is similar to that in the surrounding field, Chlorpyriphos $250 \mathrm{EC}$ was applied in $2 \mathrm{ml}$ of water at a rate of $250 \mathrm{ml} /$ acre to the soil thirty days after transplanting the rice and tricyclozole were applied on November 10th 2009. Water samples from the Lysimeter at $0.5 \mathrm{~m}$ and $1 \mathrm{~m}$ depths were collected over a period of 60 days and analyzed for nitrate phosphate and Chlorpyriphos concentration. The whole experiment was undertaken for 165 days for the Lysimeter. Lysimeter percolate was sampled every 2days. Samples were stored in a freezer when immediate analysis was not possible. The Lysimeter installed in paddy field is as shown in Fig 3.

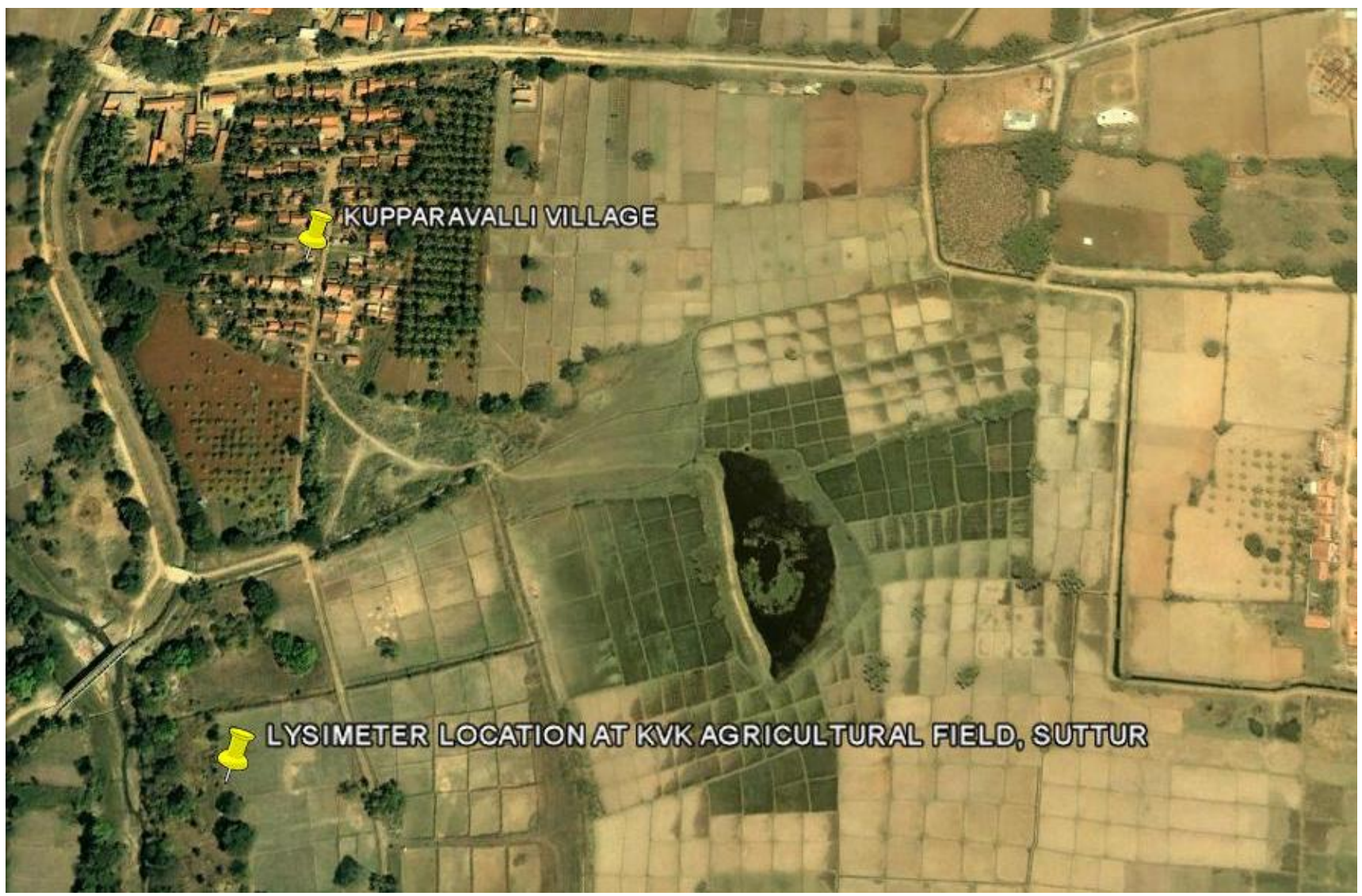

Fig -1: Location of Krishi Vigyan Kendra 


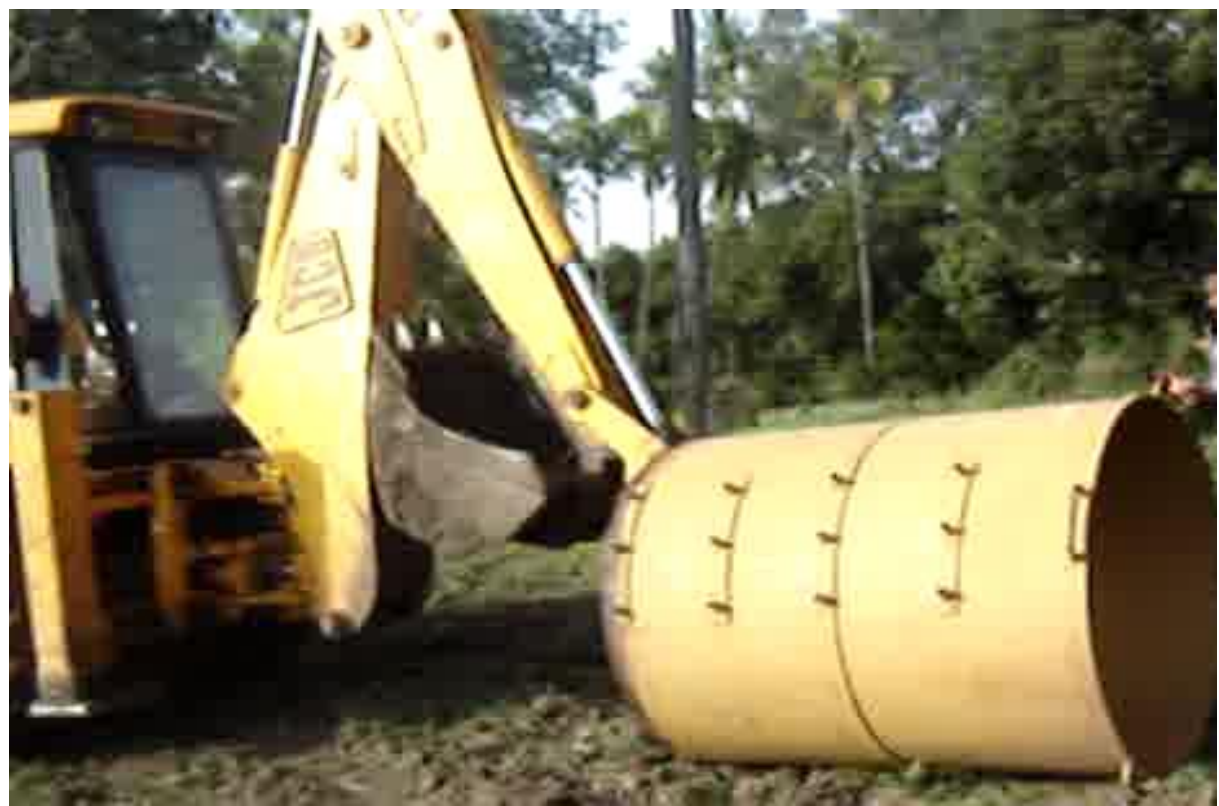

Fig -2: Lysimeter Installations
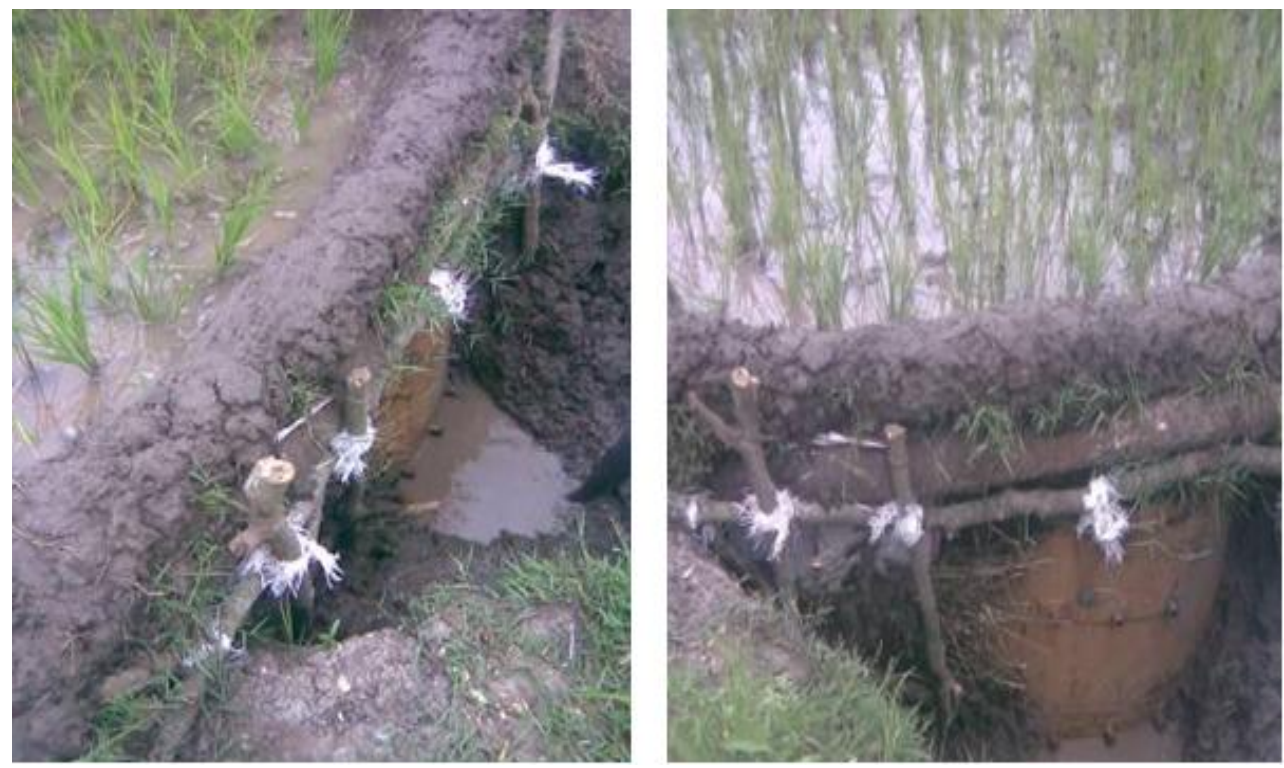

Fig -3: Lysimeter Placed in Paddy Field

\section{RESULTS AND DISCUSSION}

\subsection{Nitrate}

The nitrogen applied to wetland rice soils is usually lost through NH3 volatilization, nitrification, and de-nitrification and leaching. NH3 volatilization is an important pathway for nitrogen loss from flooded rice, however, the amount of nitrogen losses via $\mathrm{NH} 3$ volatilization from nitrogen fertilizer applied to rice are different, due to the differences in water managements, fertilization practices and experimental conditions [6]. From chart 1, the nitrate concentration at $0.5 \mathrm{~m}$ depth, at start up of the experiment, the lateral nitrate leaching was $0.56 \mathrm{mg} / \mathrm{l}$. Nitrate concentration increased gradually and reached a maximum of $3.73 \mathrm{mg} / \mathrm{l}$ on 19th day and there onwards the nitrate concentration observed to decline and reached a minimum of $0.506 \mathrm{mg} / \mathrm{l}$ on 119 th day.
Similarly, at $1 \mathrm{~m}$ depth (refer chart 2) nitrate concentration was very low initially, and observed to increase to a maximum of $0.523 \mathrm{mg} / \mathrm{l}$ on 43rd day. Thereafter, the nitrate concentration in the leachate has drastically declined and reached a minimum of $0.11 \mathrm{mg} / \mathrm{l}$ at fag end of the experiment. The current study was also substantiated by the nitrate leaching studies conducted by Zhu (2000) [7] in a paddy field up to a depth of $0.9 \mathrm{~m}$ over a period of 5 months. The higher nitrate concentration in $0.5 \mathrm{~m}$ depth was measured during third week after fertilizer application, whereas at $1 \mathrm{~m}$ depth higher nitrate concentration was noticed during sixth week. This may be due to nitrate absorbed on the soil particles and entrapped in the micro aggregates of the surface soil structure and the movement of NO3 anion is mainly by diffusion, which is comparatively a slow process. Paragraph comes content here. 


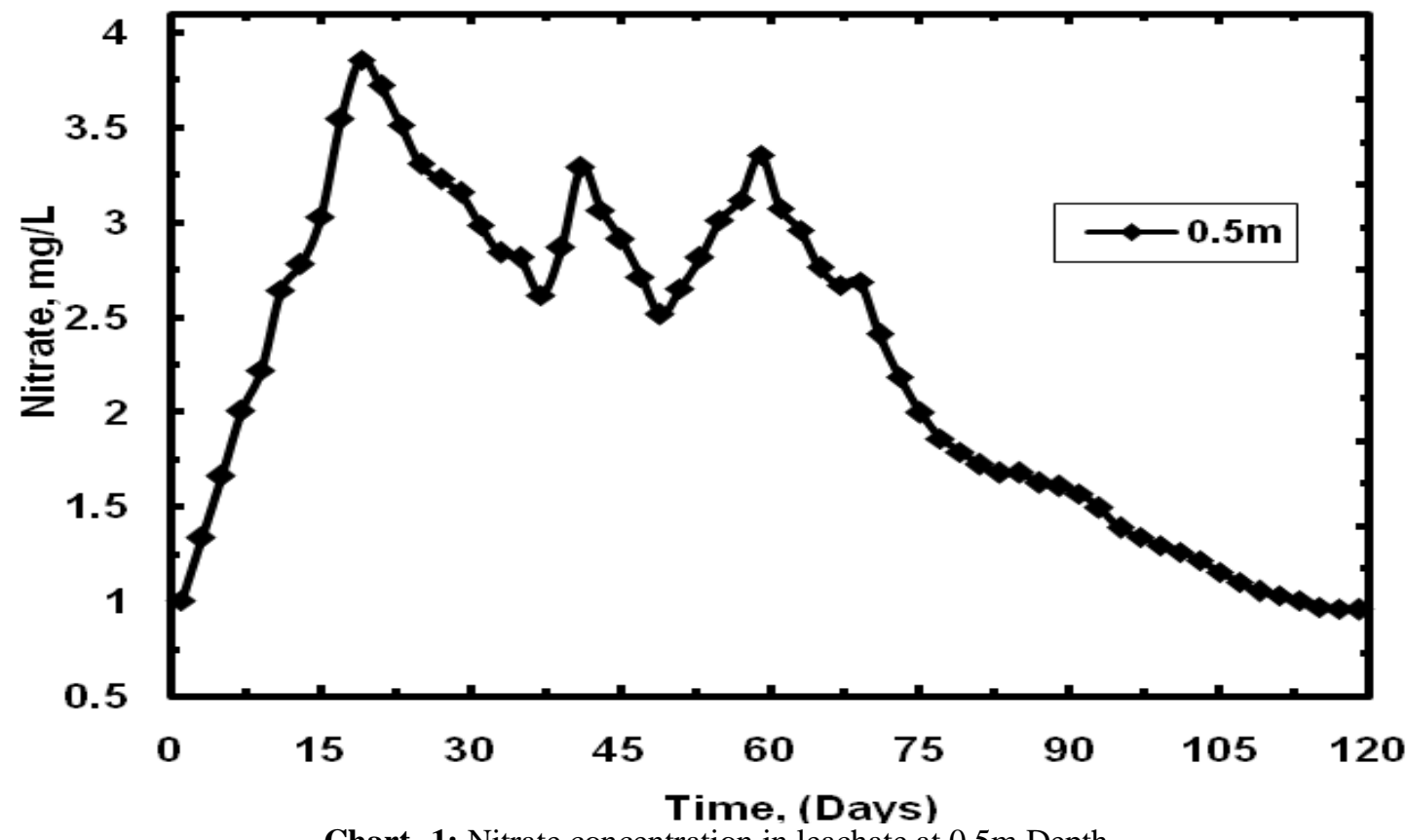

\subsection{Phosphate}

Phosphorus leaching in the paddy fields could be divided into flash leaching and slow leaching. The flash leaching occurred within the first two weeks after fertilizer application, which accounted for about $85 \%$ of seasonal phosphorus loss from the top soil and about $64 \%$ of phosphorus loss from the bottom soil. Phosphate concentrations in leachate samples of present field study at $0.5 \mathrm{~m}$ depth of soil are presented in Chart 3. The phosphate concentration observed to gradually increase with the increase in time. Similar trend was observed up to 37 th days after fertilizer application in leachate at both 0.5 and $1 \mathrm{~m}$ depth (refer Chart 4 ).

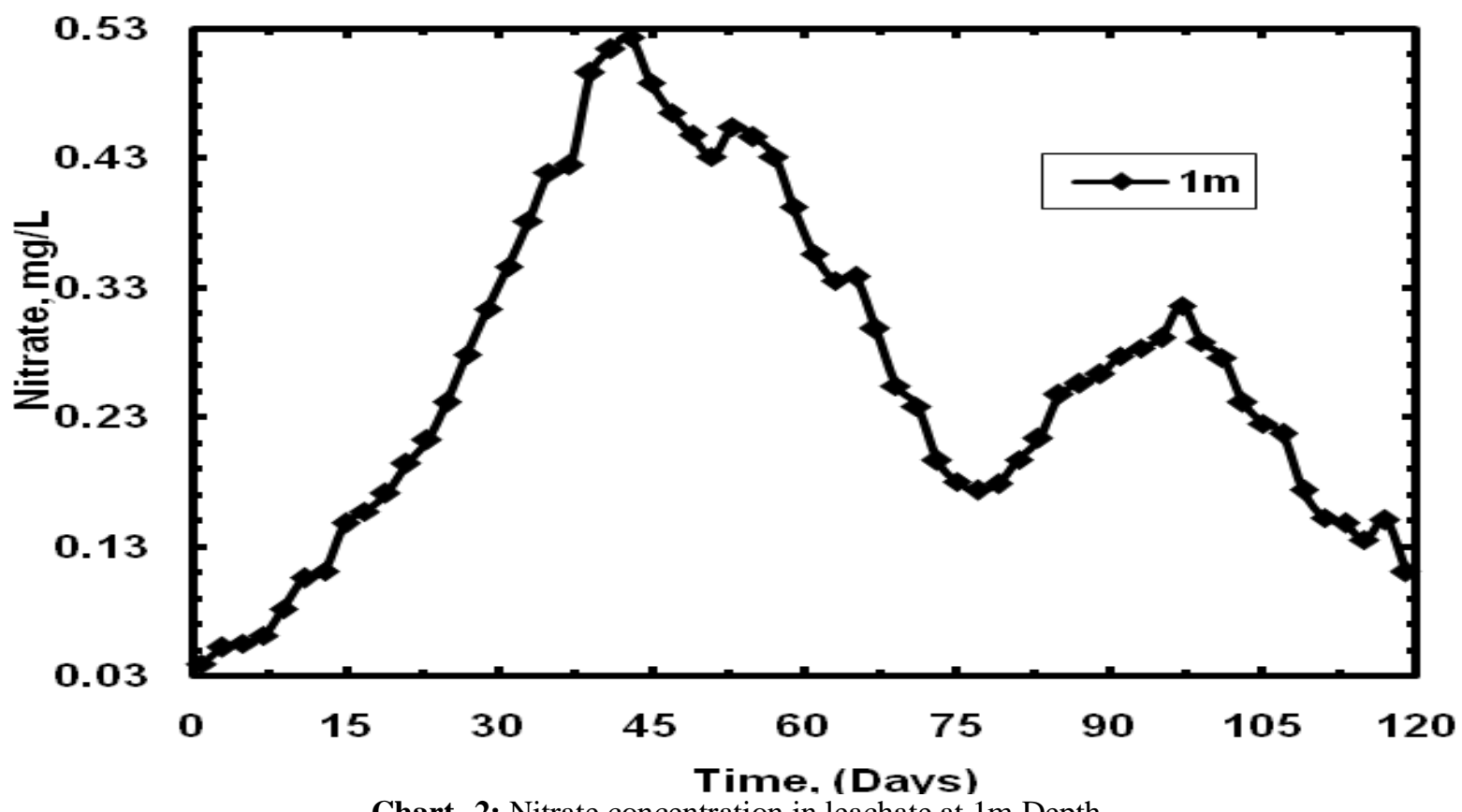

The phosphate concentration varies with depth of the soil and the highest concentrations were measured at $0.5 \mathrm{~m}$ depth when compared at $1.0 \mathrm{~m}$ depth. As the soil is clayey in nature, which mainly contains ferric and aluminum oxides and hydroxides is responsible for fixing the phosphates that mobilizes from the surface horizons. This results considerably in lowering leachate of phosphate and also high phosphate sorption within the subsoil. The current study was also substantiated by the field studies on phosphate leaching carried out by Xie et al., (2004) [8]. 


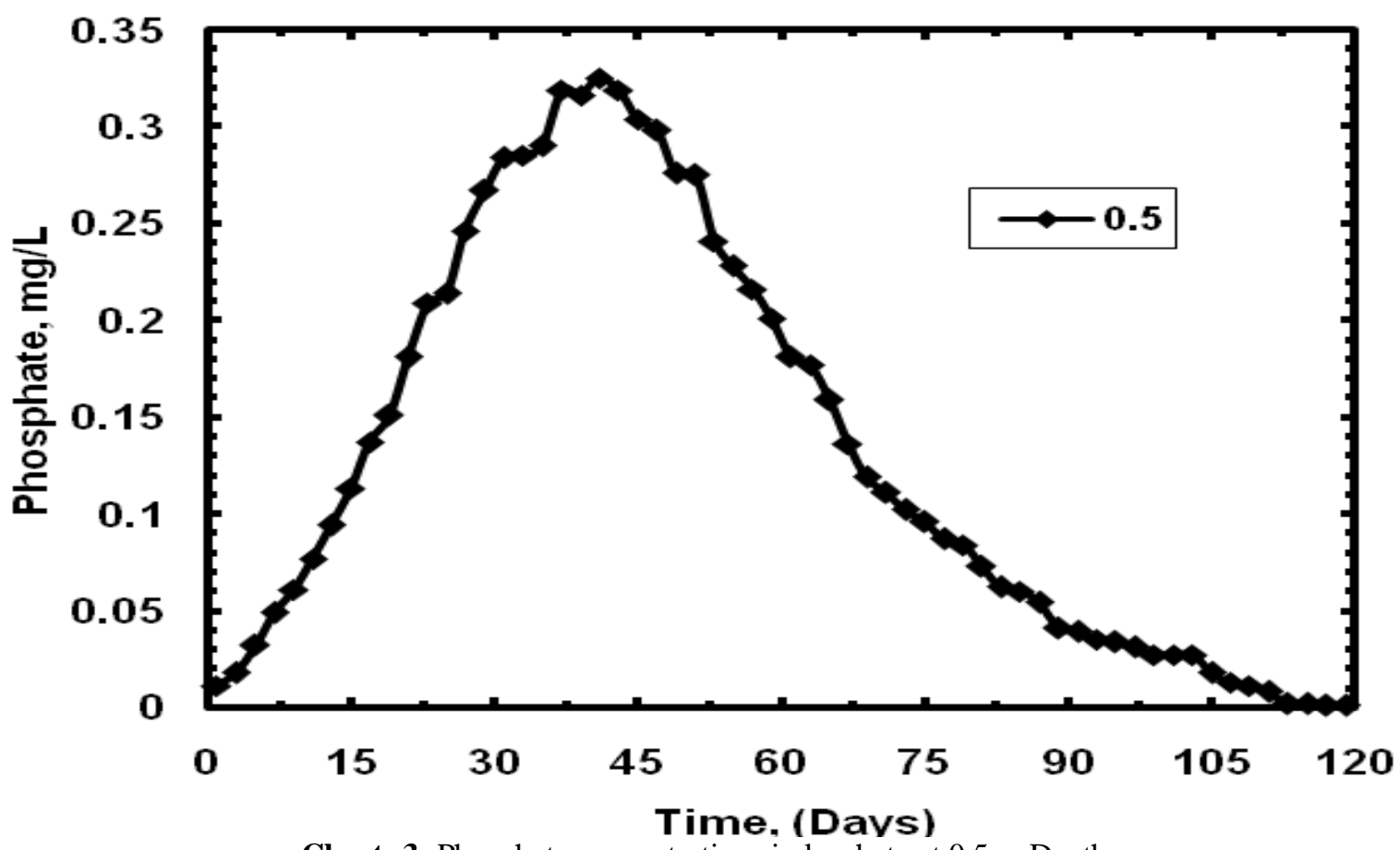

Chart- 3: Phosphate concentrations in leachate at $0.5 \mathrm{~m}$ Depth

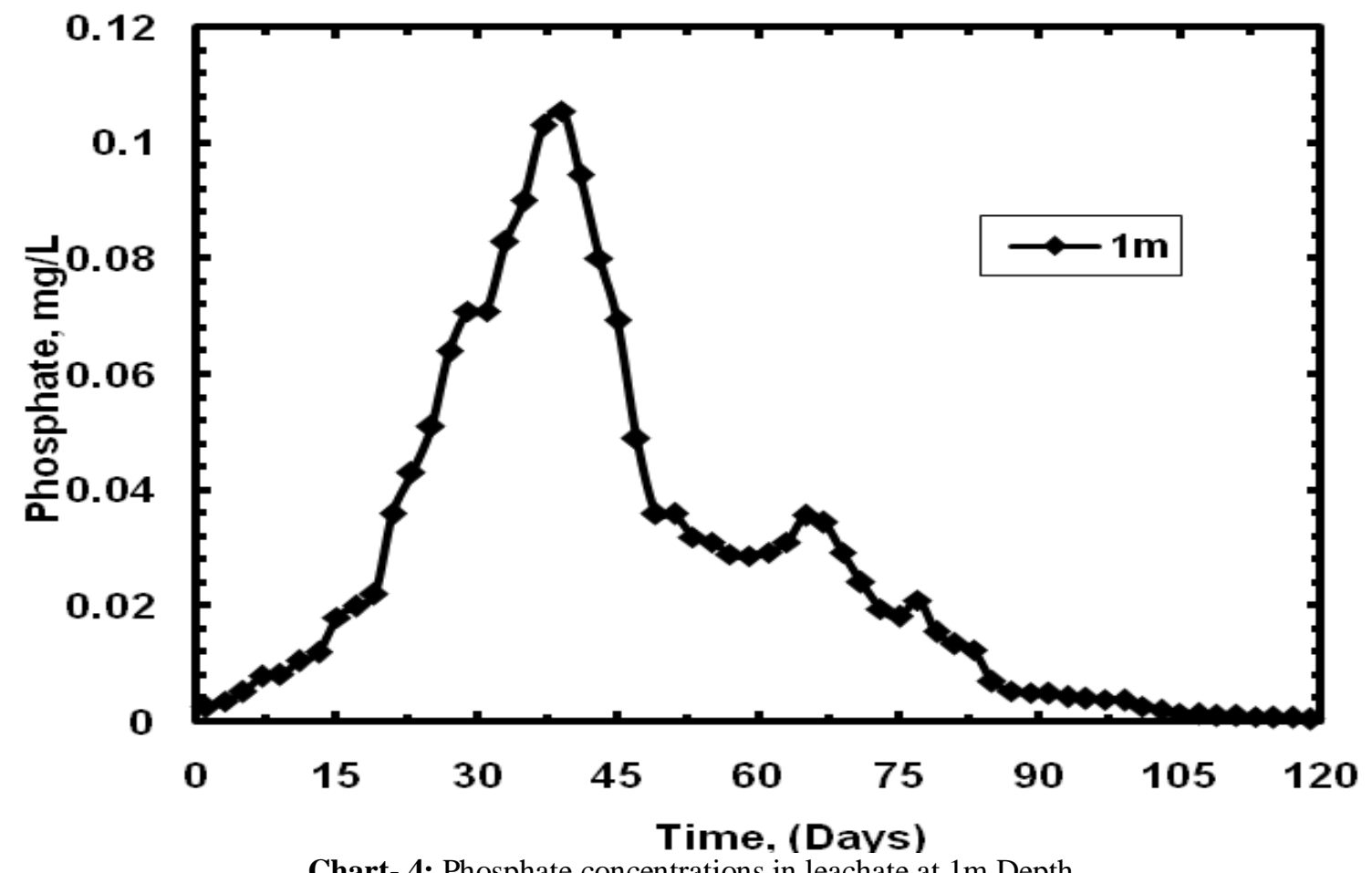

$3.3 \mathrm{pH}$

Chart- 4: Phosphate concentrations in leachate at 1m Depth

Leachate $\mathrm{pH}$ was observed to be near constant and there was slight increase from 7 to 8 at $0.5 \mathrm{~m}$ depth (Chart 5). Initially $\mathrm{pH}$ value was 7.65, and gradually increased to around 8.21 (13th day). This increase in soil solution $\mathrm{pH}$ may be due to plant root activities, as the root uptake of nitrate is likely to increase the $\mathrm{pH}$ of soil solution in the rhizosphere.

At $1 \mathrm{~m}$ depth of soil (Chart 6), the leachate $\mathrm{pH}$ did not vary in any consistent pattern and reduction of pH with time occurred in two steps. However, upto $1.0 \mathrm{~m}$ depth, the reduction in $\mathrm{pH}$ was found to be from 8.1 to 6.7. It is also noticed that the nature of the soil is acidic. This may be due to the uptake of nitrate by plants and leads to neutralization by the exertion by hydroxyl ions by plants. The slight decline in the soil solution $\mathrm{pH}$ after day 47 could be attributed to the acidifying effects of NH3 volatilization and nitrification [9]. 


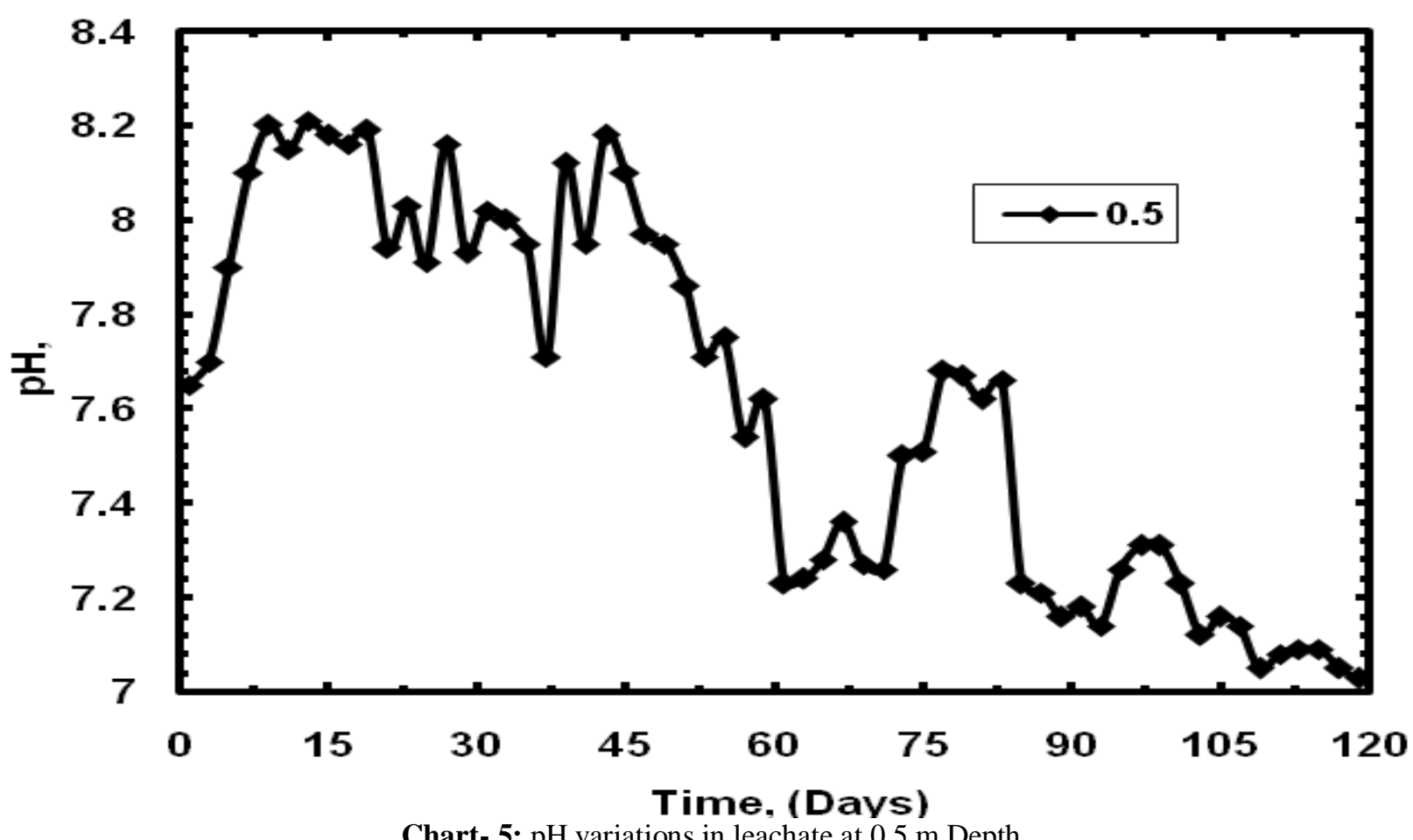

Chart- 5: $\mathrm{pH}$ variations in leachate at $0.5 \mathrm{~m}$ Depth

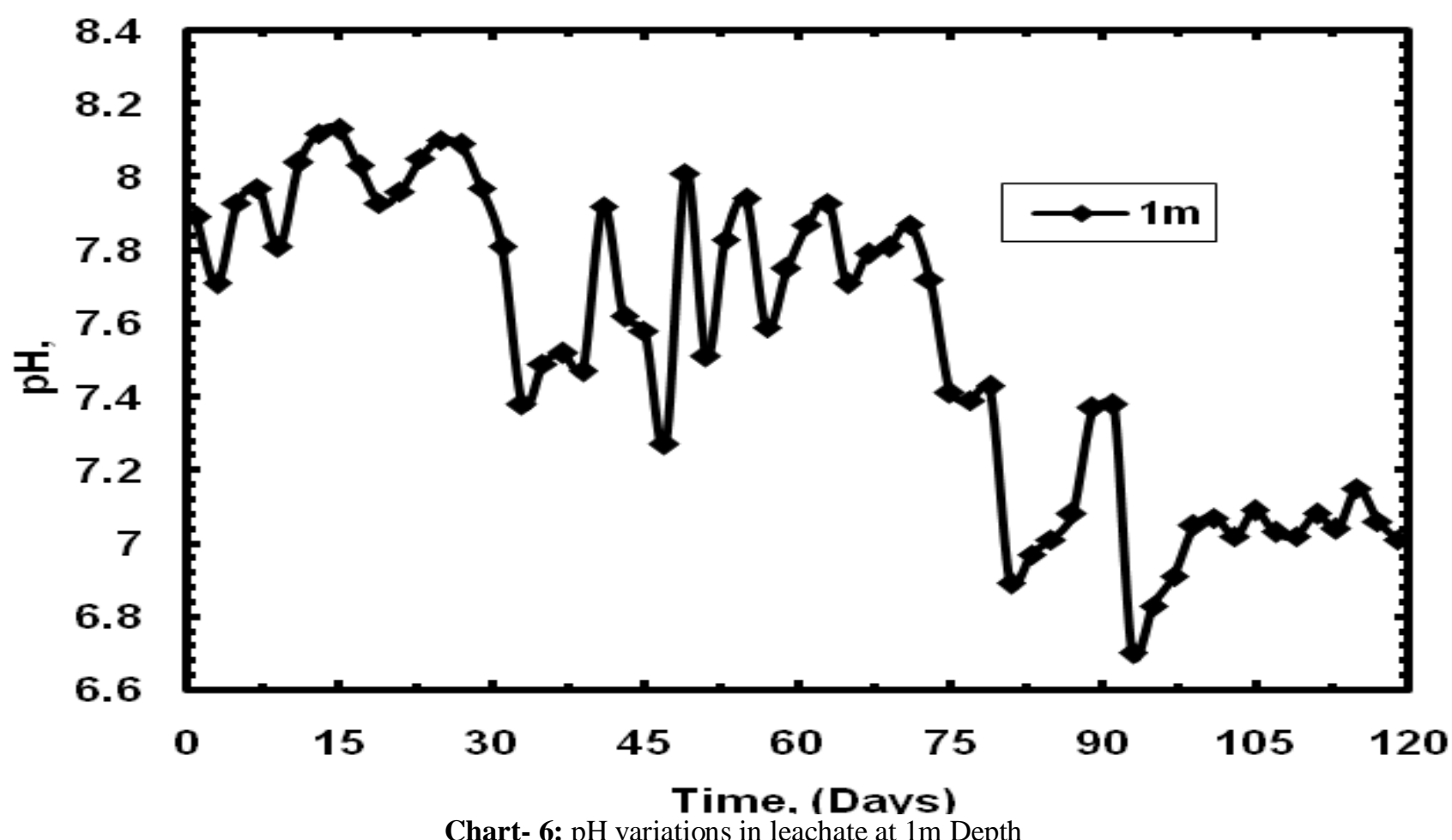

\subsection{Electrical Conductivity}

Application of fertilizer caused increase in ionic concentration which is indicated by increase in EC value in the top layers of soil (Figure 7). At $0.5 \mathrm{~m}$ depth the electrical conductivity varied with time in three stages. In the first stage electrical conductivity was near to $0.37 \mathrm{mMho} / \mathrm{cm}$ up to 30 days, between 30 and 60 days EC was near to $0.275 \mathrm{mMhos} / \mathrm{cm}$ and in third stage it reduced to minimum value of $0.25 \mathrm{mMho} / \mathrm{cm}$ between 75 and 119th days. From Figure 7 and 8 it can be noticed that conductivity at both the depth showed a fluctuation and varied from $0.26 \mathrm{mMho}$ to $0.51 \mathrm{mMho}$ at $0.5 \mathrm{~m}$ depth and at $1.0 \mathrm{~m}$ depth it varies from 0.16 mMhos to $0.31 \mathrm{mMhos}$. Therefore, it can be remarked that conductivity decreases with increase in depth of the soil. The solutes in soil solution are diluted which leads to decrease in EC. 


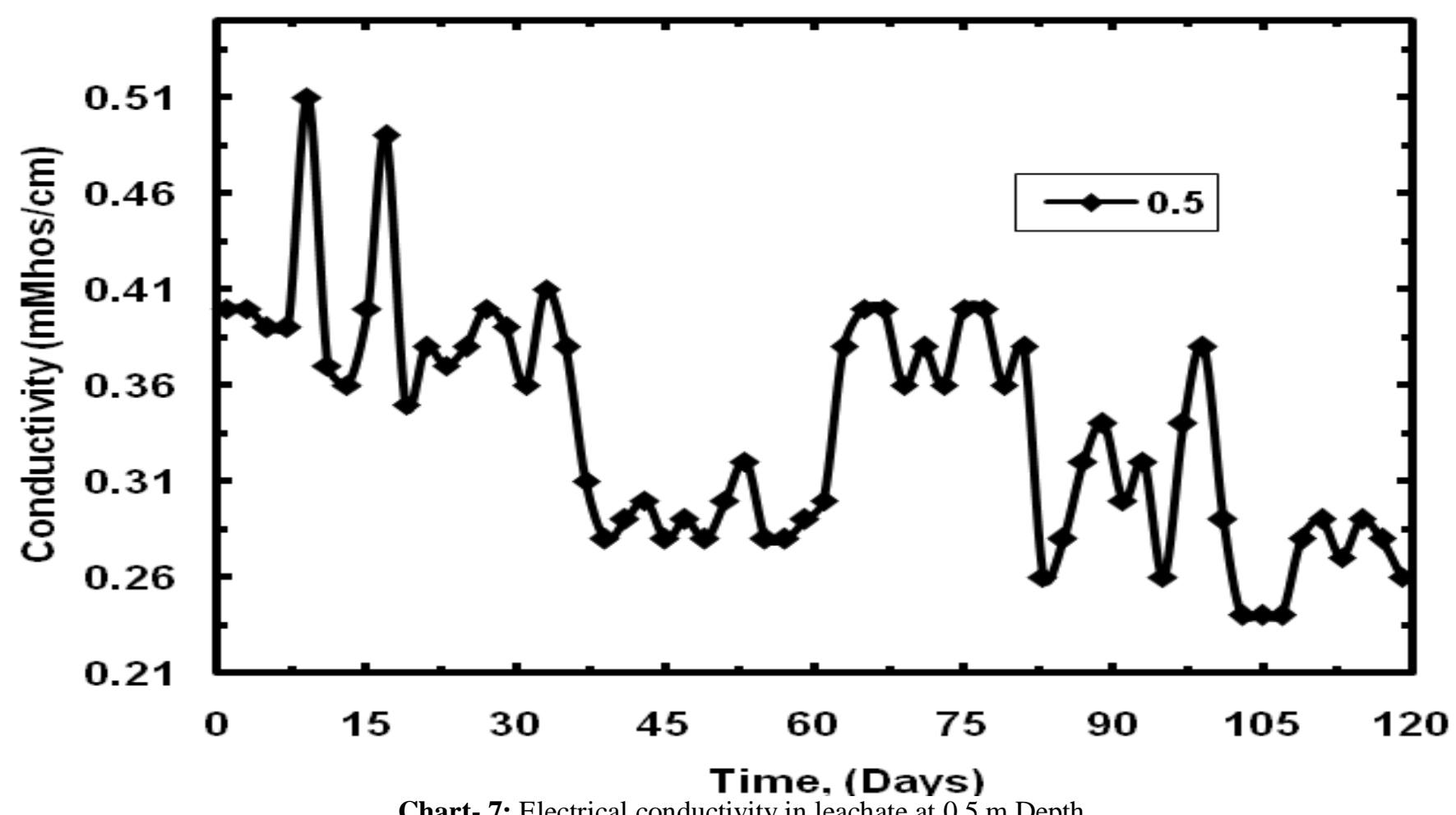

Chart- 7: Electrical conductivity in leachate at $0.5 \mathrm{~m}$ Depth

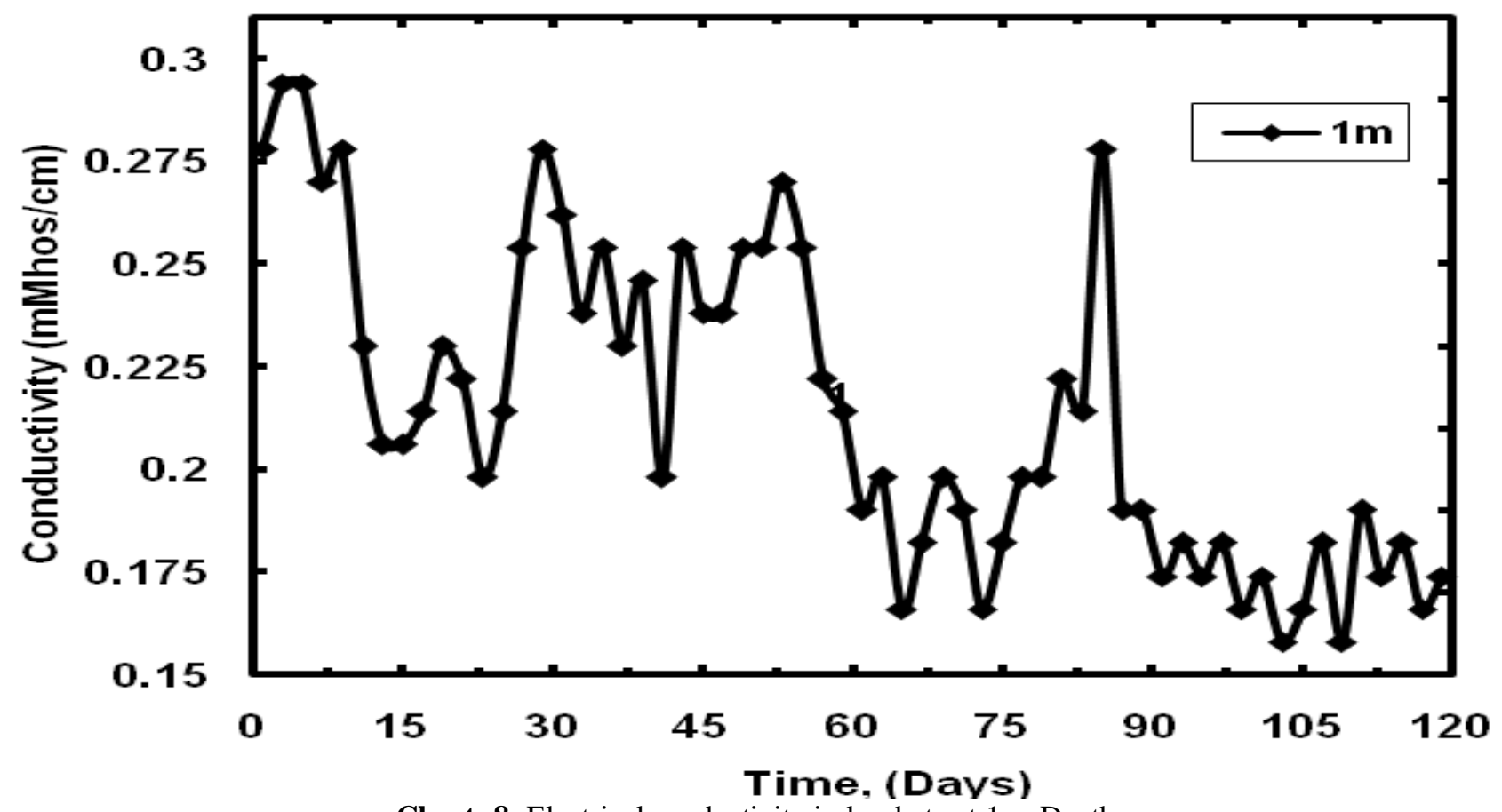

Chart- 8: Electrical conductivity in leachate at $1 \mathrm{~m}$ Depth

\subsection{Pesticide (Chlorpyriphos)}

Leaching is a fundamental property of the soil in which constituents are dissolved or suspended in soil solution phase, are lost from the soil profile through the percolating water [10]. Chlorpyriphos is a compound which can be sorbed due to its affinity towards clay minerals of the soil. From Figure 9 it is observed that the leachate of Chlorpyriphos at $0.5 \mathrm{~m}$ depth was observed on 30th day from the start up. This may be due to low mobility of
Chlorpyriphos through the soil. However, it gradually increased and reached a maximum concentration of $0.206 \mu \mathrm{g} / \mathrm{l}$ on 111 th day. Further, as the water solubility of Chlorpyriphos is hardly $2 \mathrm{mg} / \mathrm{l}$, this might influence the persistence of pesticides in soil. Due to lower solubility and higher soil adsorption characteristics, Chlorpyriphos has a very low potential of movement [8]. 
Similarly, from Figure 10 Chlorpyriphos leaching was observed on $51 \mathrm{st}$ day at $1 \mathrm{~m}$ depth. The Chlorpyriphos concentration curve at the $1 \mathrm{~m}$ depth had the same trend as was observed at $0.5 \mathrm{~m}$ depth, during first few days and but the highest Chlorpyriphos concentration was found to be at $0.5 \mathrm{~m}$ depth indicating that the pesticide (Chlorpyriphos) has very lower leaching behavior. From 41st day it gradually increased and reached a maximum of $0.12 \mu \mathrm{g} / \mathrm{l}$ at 111 thday at $1 \mathrm{~m}$ depth.
From Figure 10 it is evident that the pesticides concentration declined consistently with increased depth. This may be due to the increased adsorption results in decreased pesticides concentration in the soil leachate during the start up of the field experiment the concentrations of Chlorpyriphos in the leachate at both i.e. $0.5 \mathrm{~m}$ and $1 \mathrm{~m}$ depth was found to be very low. And also Chlorpyriphos bound more strongly to soil during initial period and also due to high soil partition coefficient $(\mathrm{Kd})$ value and low water solubility. This makes the Chlorpyriphos less available in water medium.

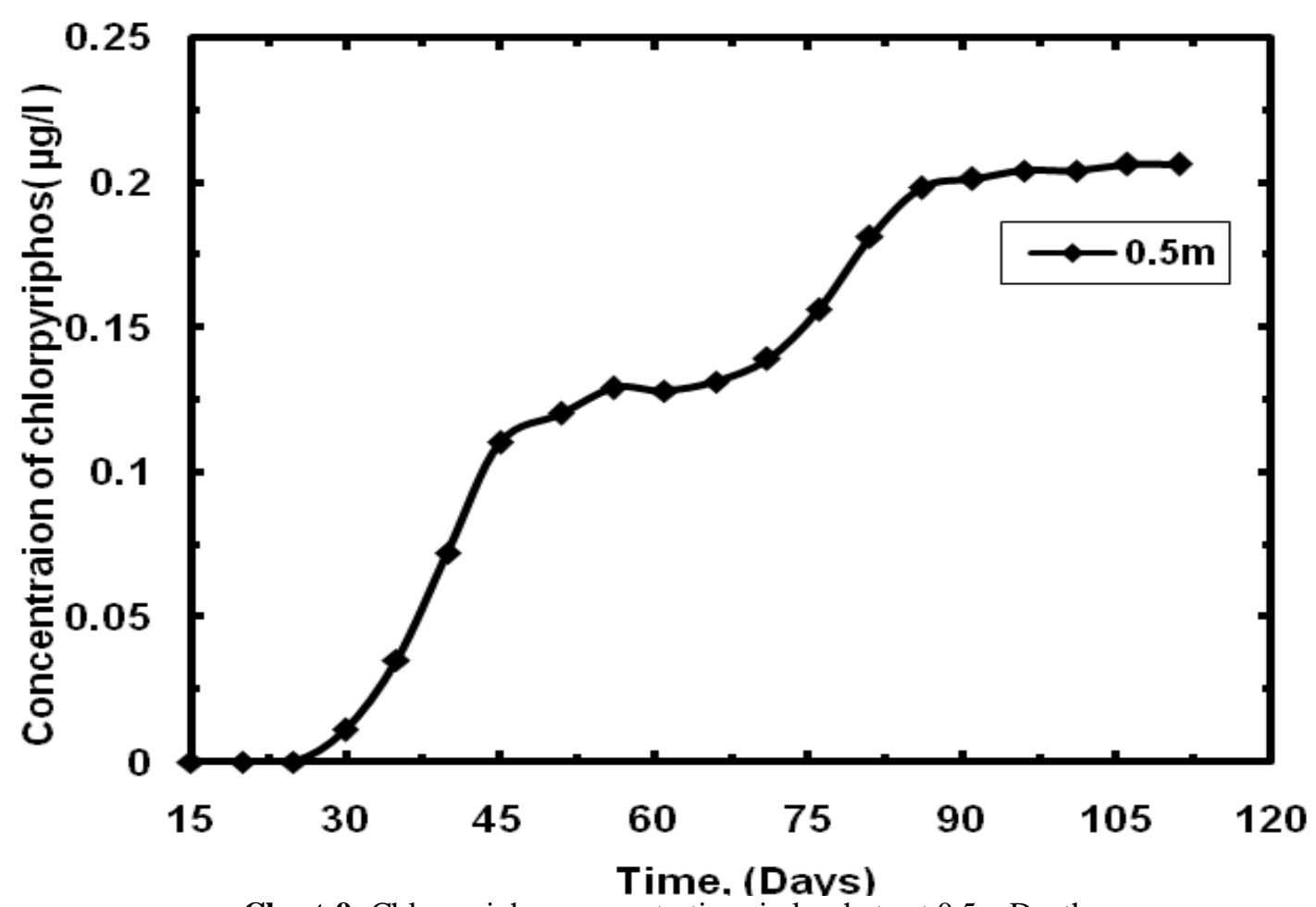

Chart-9: Chlorpyriphos concentrations in leachate at $0.5 \mathrm{~m}$ Depth

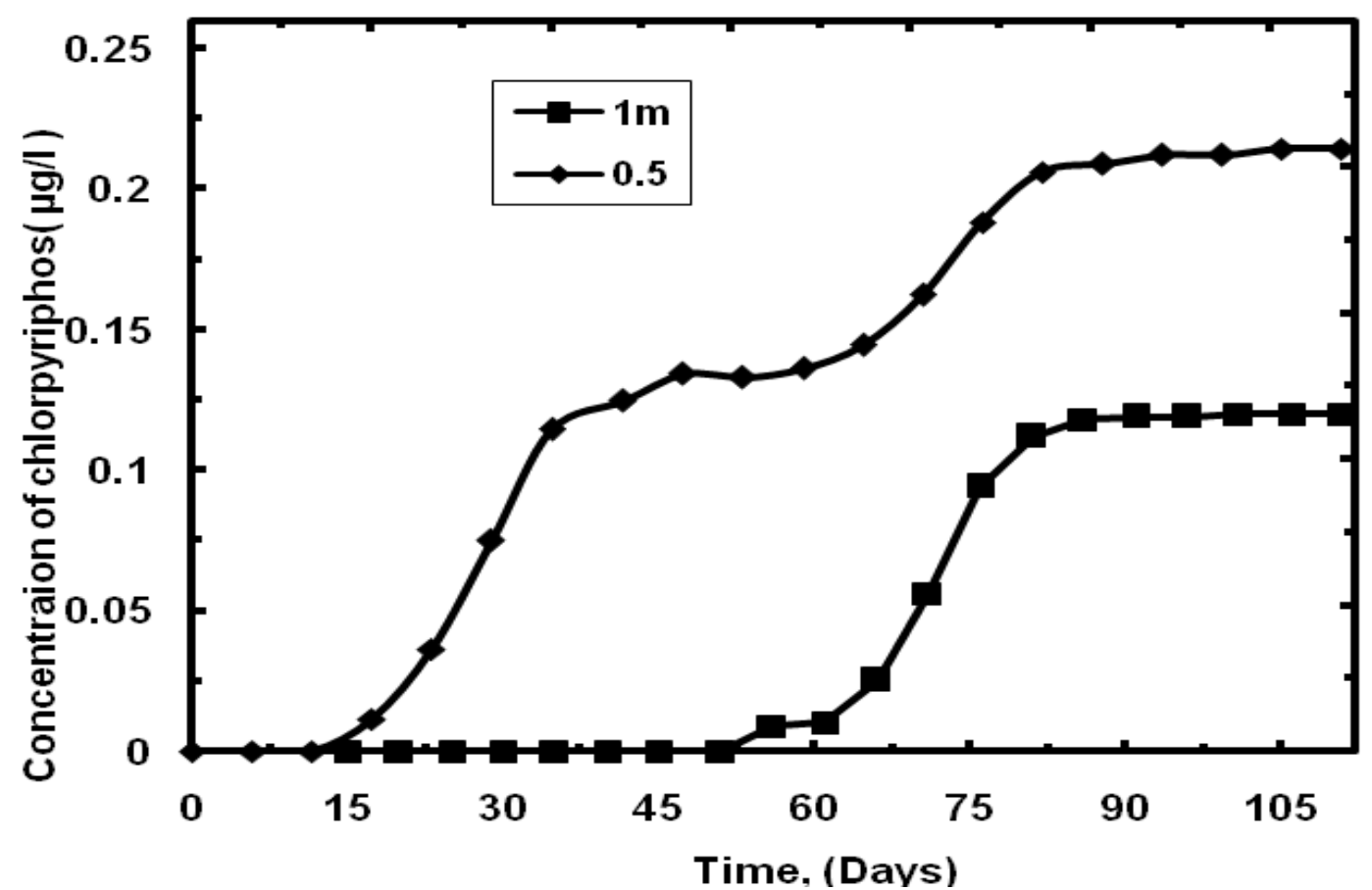

Chart- 10: Chlorpyriphos concentrations in leachate at 0.5 and $1 \mathrm{~m}$ Depth 


\section{CONCLUSION}

Nitrate content in leachate in both depths showed decreasing trend. Nitrate concentration gradually increased during initial days and thereafter it decreased as the time elapsed. The analysis of pesticide concentration in the leachate indicates that the concentration of Chlorpyriphos decreases with depth. The mobility of Chlorpyriphos in the leachate reveals that it is less mobile. Hence Chlorpyriphos is likely to affect the soil characteristics and pollute surface water bodies during runoff. Chlorpyriphos concentration shows a decreasing trend with depth this is may be due to reason as the pesticide moves through the soil it gets absorbed by organic carbon and degraded by the microorganism.

\section{REFERENCES}

[1] Karl et al., 2005. Quality criteria of the isotope dilution method for the determination of polycyclic aromatic hydrocarbons, petroleum-derived hydrocarbons and phenol in leachate of large-scale lysimeter experiments, Accred Qual Assur, Vol. 10: 229-234.

[2] Wong et al., 1998. Nitrogen and Phosphorus leaching from fertilizer applied on golf course: Lysimeter study, Water, Air, and Soil Pollution, Vol. 107: 335-345.

[3] Francaviglia R., Caprib E., 2000. Lysimeter experiments with Metolachlor in Tor Mancina (Italy), Agricultural Water Management, Vol. 44: 63-74.

[4] Park et al., 2005. Environmental Fate of the Herbicide Molinate in a Rice-Paddy-Soil Lysimeter, Bulletin Environmental Contamination and Toxicology, Vol. 75: 937-944.

[5] Sabine et al., 2008. Mineralization and Transfer Processes of 14C-labeled Pesticides in Outdoor Lysimeter, Water, Air and Soil Pollution, Vol. 8: 177-185.

[6] Cheng et al., 2008. Nitrogen losses from integrated rice duck and rice fish ecosystems in southern China, Plant Soil, Vol. 307: 207-217.

[7] Zhu e al., 2000. Nitrogen in percolation water in paddy fields with a rice/wheat rotation, Nutrient Cycling in Agro ecosystems, Vol. 57: 75-82.

[8] Xie et al., 2004. Field studies on 32P movement and $\mathrm{P}$ leaching from flooded paddy soils in the region of Taihu Lake, China, Environmental Geochemistry and Health, Vol. 26: 237-243.

[9] Adel M. G., 2008. Nitrogen Dynamics and Fertilizer Use Efficiency in Rice Using the Nitrogen-15 Isotope Techniques, World Applied Sciences Journal, Vol. 3(6): 869-874.

[10] Ngan et al., 2005, Fate of Chlorothalonil, Chlorpyrifos and Profenofos in a Vegetable Farm in Cameron Highlands, Malaysia, Water, Air and Soil Pollution, Vol. 5: 125-136. 